\title{
A Comparative Analysis of LEED and GPRS for the Applicability in Egyptian Office Buildings
}

\author{
Eman M. E. Attiya, Mohamed A. Shebl, and Maii M. Nasser \\ Department of Architecture, Faculty of Engineering, \\ Menoufia University, \\ Menoufia, Egypt.
}

\begin{abstract}
The purpose of this study is to analyze and evaluate the credits of GBRSs to achieve sustainability in office buildings in Egypt to determine the most effective and applicable system in Egypt. The study followed the qualitative research method and mainly consisted of three stages, the theoretical approach followed by a comparative analysis and case studies. Four Egyptian LEED-certified projects which were all LEED BD+C: NC certified and categorized as office buildings were analyzed and reevaluated using the Egyptian GPRS to find their achievable certification level. LEED rating system was found to have a more accurate representation of sustainability when compared to GPRS in terms of certification levels awarded. Therefore, it was concluded that LEED is a more suitable option for Egyptian office buildings. However, GPRS appoints more points for water efficiency which is a priority as Egypt faces problems with water supply and demand. Therefore, GPRS is suitable for Egyptian projects in general, not office buildings specifically. This study is of significance due to the lack of studies which analyze the pillars of sustainability GPRS addresses in comparison to LEED. The results for this study have significant implementation recommendations for the Unified Building Law and its Executive Appendix, GPRS (2016), and stakeholders.
\end{abstract}

Keywords-Comparative Analysis, GBRS, LEED, GPRS, Office Buildings, Unified Building Law.

\section{INTRODUCTION}

Sustainable architecture can be defined as architecture which aims to reduce the negative impact of buildings which can be achieved by the efficient use of resources, materials, energy, water, and the ecosystem. The concept of a sustainable building was defined by the United States Environmental Protection Agency as the use of environmentally responsible and resource-efficient processes throughout a building's lifecycle. Whereas, Brundtland defined sustainable development as a development that satisfies the present needs whilst preserving the resources for the next generations' needs. Most rating systems were developed based on the main pillars of sustainability which are the environment, society, and economy.

The construction industry is considered of importance to sustainable development as it requires energy, water, sites, and materials to construct and operate. Therefore, the construction industry has direct and indirect effects on the environment. The existing literature indicates that buildings and the construction sectors are responsible for $36 \%$ of global energy consumption. They are also responsible for approximately $40 \%$ of total $\mathrm{CO}_{2}$ emissions. Office buildings are large consumers of energy as they require large amounts of electricity for lighting, air conditioning, and workstations. They consume almost twice as much energy as residential buildings. Therefore, this study addresses achieving sustainability in office buildings exclusively in Egypt.

Green Building Rating Systems (GBRSs) have been established rapidly worldwide to evaluate the sustainability level of green buildings. Leadership in Energy and Environmental Design (LEED) was introduced in 1998 and has become one of the most prominent rating systems worldwide. LEED gives priority to the energy category as it is given the highest weighting share. The Egyptian Green Pyramid Rating System (GPRS) was first introduced in 2011. GPRS was introduced to initiate the construction of green buildings in Egypt. The lack of government policies, codes and incentive programs in Egypt play an important role in the hindrance of GBRSs locally. During the construction and planning stages, decision-makers/architects do not take into account the impact of buildings on the environment throughout their lifecycle. Examples of the applicability of GPRS in Egypt have been rare since its release in 2011. The purpose of this study is to conclude the applicability of GBRSs in Egypt in relation to the current Egyptian laws that relate to construction.

\section{METHODOLOGY}

The research follows the qualitative research method. To find the most suitable GBRS for Egypt the research adopted a variety of approaches which include the theoretic approach, comparative analysis, and case studies. The theoretic approach includes a thorough understanding of green buildings and sustainability, an overview of various rating systems, and a review of the literature. Following the theoretic approach, a thorough comparative analysis between the American rating system (LEED) and the Egyptian rating system (GPRS) is carried out to identify all aspects of the systems including goals, objectives, assessment methods, and effectiveness. The Egyptian building codes are also reviewed to identify the articles which may affect the implementation of rating systems in Egypt. The comparative study is carried out in two phases, as shown in Figure 2. The first phase presents the general characteristics of both rating systems followed by the second phase which includes an in-depth thorough comparison, including; assessment of the categories, aspects of sustainability, assessment criteria, cost of assessment, validity, adaptability, and lifecycle stage coverage. 


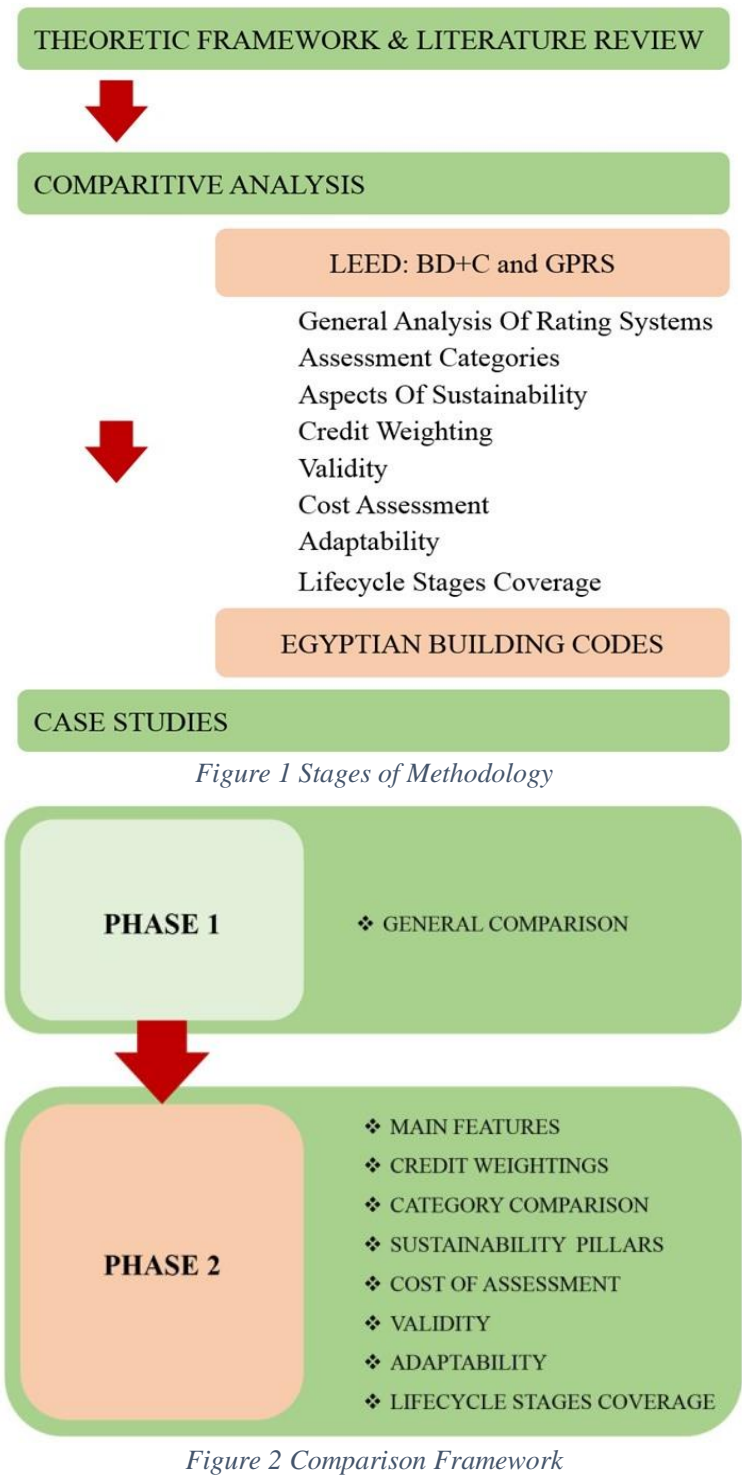

\section{LITERATURE REVIEW}

The awareness and interest surrounding the concept of green buildings and sustainability have increased as of late. GBRSs have been the focus of several studies during the past couple of years. The number of GBRSs have increased with countries developing rating systems based on the conditions and characteristics of the region. Alyami and Rezgui [1] found that climatic and geographic conditions, renewable energy sources, regulations and legislations, and population growth rates were taken into consideration when developing a rating system.

Abdel Aleem et al. [2] assessed the energy credits of BREEAM, LEED, Green Star, and the PEARL rating systems in order to improve the GPRS. The results indicated that including the following as mandatory energy credits to enhance GPRS will yield the most effective results in Egypt; minimum energy performance (credit 1), fundamental refrigerant management (credit 2), and fundamental commissioning of building energy systems (credit 8). Optimized energy performance (credit 6) was excluded from the suggested mandatory credits as it is difficult to force customers to conform to both credits 1 and 6 . The suggested mandatory energy credits happen to coincide with the prerequisites found in LEED. However, the credits do not mirror that of PEARL and GPRS.

Ammar [3] carried out a comparative analysis of international GBRSs including SANS of South Africa, Estidama of the United Arab Emirates, QSAS of Qatar, LEED of the United States, and the Egyptian GPRS to evaluate the Egyptian rating system. After analyzing the five rating systems the researcher concluded that the relative criteria weightings of each rating system differed based on the vision of each system. The systems were found to be led by the local problems the country of origin faces which affects the distribution of the credits. Where Estidama prioritizes preserving the natural environment of the project and enhancing biodiversity while SANS gives importance to solving global environmental problems by adding criteria to address the issue of gas emissions which is the leading cause of global warming.

El Yamany et al. [4] examine the implementation of the LEED credits in Egypt. A comparative analysis was carried out on LEED-certified projects constructed in Egypt. The results indicate that LEED can be used to promote sustainability in buildings in addition to evaluating them. They emphasize the significance of acclimating to the local needs and considerations including climate, social, cultural, environmental, and economic aspects in any local rating system. The study presented the most attained and targeted credits within projects in Egypt.

He et al. [5] investigate the relationship between green design and GBRSs. The impact of implementing GS on the design of a project in Australia is compared with the impact of implementing LEED in the United States, and ASGB in China. The comparison is carried out on a GS Six Stars certified case study, the Melbourne School of Design building (MSD). The study concluded that LEED is an energy-oriented environmental rating system while GS and ASGB both emphasize energy and indoor environment quality. LEED and ASGB were found to be design-guide systems which provide strategies and measures that can be taken into account. However, GS was found to be a performance-based system which permits freedom in the design stage. MSD received a sixstar certification with GS, a gold certification with LEED, and a two-star rating with ASGB further proving that GBRSs differ in evaluation and criteria required.

Shamseldin [6] evaluates the compatibility of using international rating systems and their energy credits with Egyptian energy efficiency codes to help enforce the most suitable and effective system in Egypt. The Egyptian code requirements represent the most appropriate standards for Egyptian buildings to abide by. The study indicates that the international rating systems (LEED, BREEAM, and Green Star) don't reflect the required environmental results when used in other countries, thereby becoming a marketing technique. It also showed that replacing LEED in Egypt with the Egyptian method may incur effective environmental results and that Green Star is the most appropriate system to reflect energy efficiency based on the Egyptian requirements.

Shamseldin [7] sheds a light on the prospect of including coordination variables in GPRS to provide a higher level of accuracy with environmental assessment results. Two gated 
communities were selected in different regions in Egypt. The study proposes having a variety of versions of each rating system which are specifically oriented for each region to guarantee a higher level of accuracy in the results provided by the rating systems. The study concluded that the major difference lies in the needs of the energy \& water categories. Thus, a project in Aswan which has been certified may not be in Marsa-Matrouh and vice versa.

Ali and Al Nsairat [8] provided a clear understanding of GBRSs and their role in sustainable development. The rating systems analyzed were LEED, CASBEE, BREEAM, GBTool, and others. The study focused on the role of rating systems in residential units in Jordan, focusing on the region's requirements. The research proposed SABA, a GBRS which is suitable for the environmental, social, and economic conditions in Jordan. The proposed SABA system prioritizes water and energy efficiency due to Jordans' lack of resources. The main categories of SABA are site, energy efficiency, water efficiency, material and resources, indoor environmental quality, waste and pollution, and economics. Although the other GBRSs do not factor economics as the main category, it contributes $10 \%$ in SABA. SABA is restricted to residential buildings it also does not include operation and maintenance stages as opposed to LEED and other rating systems.

Illankoon et al. [9] identify the key credits for GBRSs and compare the way each system deals with them. Each GBRS assesses buildings with a variety of different criteria. The key credits were identified and assessed based on the following eight GBRSs; LEED, BREEAM, Green Star, GBI, Green Mark, BEAM Plus, IGBC rating, and CASBEE. LEED, Green Mark, and GBI were found to have similar approaches to point distribution while BREEAM and Green Star show similar approaches. As opposed to other rating systems, CASBEE has a unique approach to point distribution. The study found that some rating systems highlight specific credits which may result in projects being certified by solely achieving that criterion while overlooking the rest which is vital to achieving sustainability.

Alyamia and Rezguib [1] investigate international GBRSs (BREEAM, LEED, SBTool, and CASBEE) to identify the effectiveness and differences between them to create a model which can help develop a rating system for Saudi Arabia. The criteria in each rating system were compared to help derive a set of criteria to develop a suggested Saudi Arabia rating system model. The new rating system model was designed to include categories from SBTool and CASBEE, such as economic features and quality of service as well as the most important categories in BREEAM \& LEED.

Khese et al. [10] present a comparative analysis of GBRSs, specifically BREEAM, LEED, Green Star, and GRIHA. GRIHA was developed in 2007 in India. The study takes into account the rating systems as a whole to find the most effective system providing an understanding to help stakeholders make a decision about the most appropriate version to implement. The rating systems analyzed differ in several ways in terms of the process of certification, cost, data collection, etc. The study concluded that although the rating systems aren't unique in nature, they were founded on different parameters and have different results when rating the same project. Khese et al. found that the rating systems don't express the effectiveness of the project and can be arranged in terms of suitability and effectiveness as follows LEED, BREEAM, GRIHA, and Green Star.

Nguyen and Altan [11] present a comparison between five GBRSs, specifically BREEAM, LEED, CASBEE, Green Star, and HK-BEAM. The study included several aspects when comparing the systems such as identifying the process of evaluation for each system, their weightings, rating levels, lifecycle assessment, the complexity of each system, and the effectiveness of the system. After the evaluation of the rating systems as a whole, the study concluded that BREEAM and LEED scored the highest in total while Green Star scored the lowest followed by HK-BEAM.

Doan et al. [12] present an assessment of the development of GBRSs (LEED, BREEAM, CASBEE, and Green Star NZ). They identified the similar and differing aspects of each system as well as their strengths and weaknesses. The rating systems were also assessed to find out whether they address all the pillars of sustainability. Doan et al. (2017) found that none of the assessed GBRSs take into consideration all aspects of sustainability. BREEAM, which was the first rating system developed, was concluded to be the strongest as it takes into account environment, society, economy, and institution while Green Star NZ is the weakest as it focuses solely on the environment. The social aspect was found to be critically assessed in LEED while CASBEE balances environmental, social, and economic aspects.

Based on existing literature and the above arguments, some studies criticize systems as a whole to specify the best system. Doan et al. [12] and Awadh [13] analyzed GBRSs to find out whether they address all the pillars of sustainability, however, no such studies have been conducted relating to GPRS and sustainability. Whereas, Khese et al. [10] and Nguyen and Altan [11] compared GBRSs to find the most effective system to provide a better understanding to help stakeholders make a decision about the most appropriate system to implement. However, no such studies were carried out with the Egyptian rating system GPRS. Therefore, a comparative analysis will be carried out between LEED and GPRS as they relate to Egypt. According to the contingency theory, the requirements of rating systems differ according to location and environment. Therefore, it is required to study the effectiveness of GBRSs in Egypt and their effect on sustainability.

\section{RATING SYSTEMS}

\section{A. LEED BD+C}

The USGBC is a non-profit trade organization which aims to promote sustainability in building design, construction, and operation. USGBC developed the LEED rating systems and Green Build. LEED [14] was designed to make green buildings market-driven instead of being required by regulations, thereby making the building owners the ultimate authorities which have resulted in the system's success. They are a set of environmental and sustainable construction guidelines that aim to create sustainable, high-performance buildings. It can have 
social benefits by creating healthier environments and communities. LEED can also have economic benefits in addition to environmental benefits through utility savings from energy and water efficiency.

LEED is a comprehensive and flexible system which makes it relevant to buildings at any stage in their lifecycle. It addresses a variety of different types of projects with different rating systems tailored to each type including Building Design and Construction $(\mathrm{BD}+\mathrm{C})$, Interior Design and Construction $(\mathrm{ID}+\mathrm{C})$, Operation and Maintenance $(\mathrm{O}+\mathrm{M})$, Homes, Neighborhood Development (ND), Cities \& Communities, LEED Recertification, and LEED Zero. Each LEED rating system consists of prerequisites and credits under each category. Prerequisites are mandatory requirements and key criteria which must be achieved for the project to be certified otherwise the project cannot be certified while credits are project characteristics, measurements, values, or functions identified in a LEED rating system which represent different facets of sustainability. Projects which apply for LEED certification must meet a few minimum program requirements (MPRs) to determine if the project is eligible for LEED.

This research analyzes three different versions of LEED BD+C: NC, specifically LEED v2009 [15], LEED v4 [16], and LEED v4.1[17]. LEED v4.1 is the latest version of LEED and was published in January of 2020. It includes minor changes in comparison to LEED v4. In terms of category weights, LEED v4.1 has experienced no changes when compared to LEED v4 category weights. However, it has had changes with applicable and achievable credit requirements throughout the rating system. The rating system is divided into nine main categories.

\section{B. Green Pyramid Rating System (GPRS)}

The introduction of a GBRS plays a significant role in promoting sustainable green building development. In 2011, GPRS was established to meet the need for an Egyptian green building assessment system by the Housing and Building National Research Center (HBRC). It is a national rating system for buildings which provides criteria to evaluate and rate the environmental performance of projects. The system should also assist the stakeholders to make informed decisions. The Egyptian GPRS was updated in 2016 with major changes applied to it in terms of category contents and weightings. The rating system is divided into seven categories with innovation as a bonus category.

\section{COMPARATIVE ANALYSIS}

This section includes an analysis of several aspects between LEED BD+C: New Construction and Major Renovations v2009, v4, and v4.1 in addition to the First Edition of GPRS [18], and the Second Edition of GPRS [19].

\section{A. Main Features}

Table 1 presents the main features of each system providing a brief comparison of the rating systems.

\section{B. Category Weighting}

LEED v4 and v4.1 give priority to energy efficiency with $30 \%$ followed by location and transportation and IEQ with $14.5 \%$ each while LEED v2009 also prioritizes energy efficiency with $32 \%$ followed by sustainable sites and IEQ with $23.5 \%$ and $13.5 \%$ respectively. The updated GPRS (2016) no longer prioritizes the water category over the remaining categories, it prioritizes energy efficiency with $30 \%$ followed by water efficiency with $22 \%$. Figure 3 presents the category weightings (as percentages) of each system.

\section{Table 1 Main Features of LEED \& GPRS}

\begin{tabular}{|c|c|c|}
\hline CATEGORIES & LEED BD+C: NC & GPRS \\
\hline Country & United States of America & Egypt \\
\hline Organization & USGBC & HBRC \\
\hline Flexibility & 160 Countries & 1 Country \\
\hline First Version & 1998 & 2011 \\
\hline Latest Version & 2020 & 2016 \\
\hline $\begin{array}{c}\text { Main } \\
\text { Categories }\end{array}$ & $\begin{array}{l}\text { Location \& } \\
\text { Transportation } \\
\text { Sustainable Sites } \\
\text { Water Efficiency } \\
\text { Energy \& Atmosphere } \\
\text { Materials \& Resources } \\
\text { IEQ } \\
\text { Innovation } \\
\text { Regional Priority }\end{array}$ & $\begin{array}{l}\text { Sustainable Site } \\
\text { Energy Efficiency } \\
\text { Water Efficiency } \\
\text { Materials \& Resources } \\
\text { IEQ } \\
\text { Management } \\
\text { Innovation }\end{array}$ \\
\hline $\begin{array}{l}\text { Assessed } \\
\text { Buildings }\end{array}$ & $\begin{array}{l}\text { Residential } \\
\text { Schools } \\
\text { Retail Buildings } \\
\text { Commercial Buildings } \\
\text { Multifunction Buildings } \\
\text { Healthcare Facilities }\end{array}$ & New Construction \\
\hline Rating Level & $\begin{array}{c}\text { Certified } \geq 40 \\
\text { Silver } \geq 50 \\
\text { Gold } \geq 60 \\
\text { Platinum } \geq 80\end{array}$ & $\begin{array}{c}\text { GPRS }-\mathbf{2 0 1 1 :} \\
\text { Certified } \geq 40 \\
\text { Silver } \geq 50 \\
\text { Gold } \geq 60 \\
\text { Green } \geq 80 \\
\text { GPRS }-\mathbf{2 0 1 6 :} \\
1 \text { Pyramid } \geq 30 \\
2 \text { Pyramids } \geq 40 \\
3 \text { Pyramids } \geq 50 \\
4 \text { Pyramids } \geq 60 \\
5 \text { Pyramids } \geq 80\end{array}$ \\
\hline
\end{tabular}




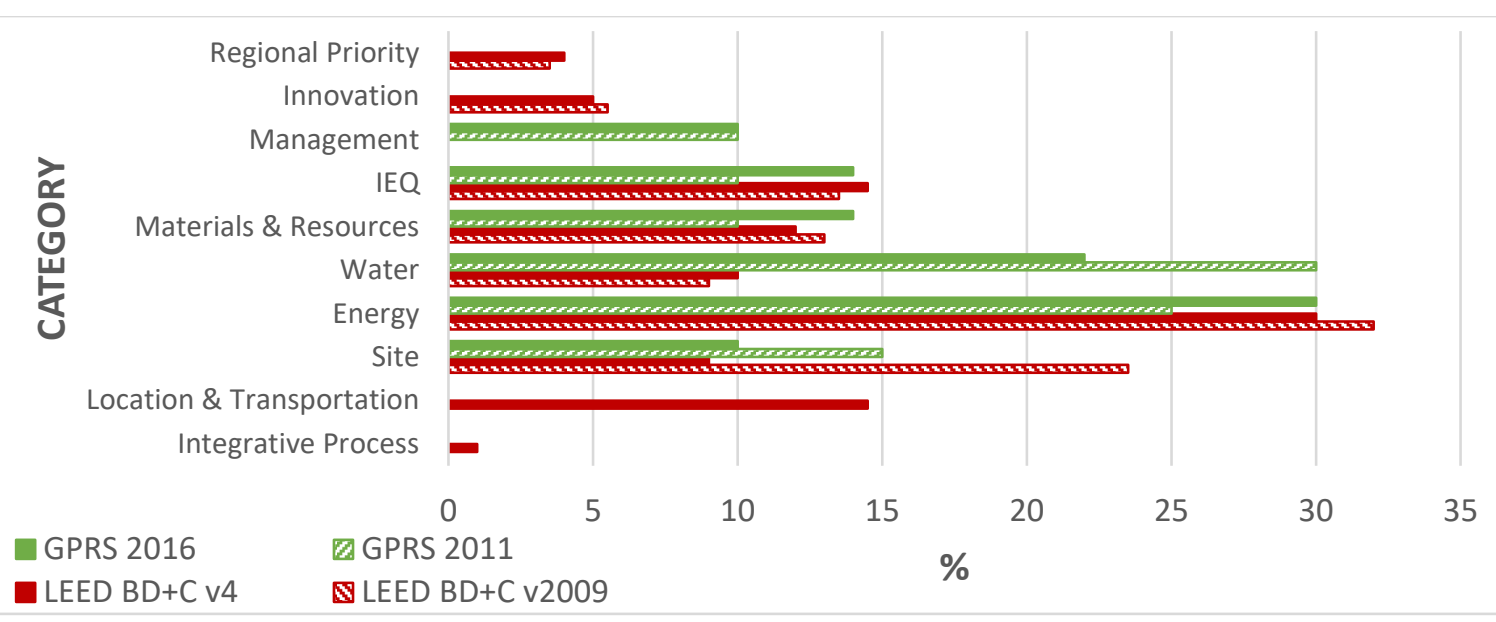

Figure 3 Category Weightings of LEED \& GPRS

\section{Category Contents}

The category contents and issues addressed by LEED and GPRS are analyzed to identify their strengths and shortcomings.

\section{1) Location and Transportation}

Both versions of the Egyptian rating system address several of the issues in this category although they do not include this category, as presented in Table 2. GPRS 2011 doesn't include credits aimed towards avoiding development on inappropriate sites and environmentally sensitive lands as opposed to LEED and GPRS 2016. However, GPRS addresses conserving/protecting historic and cultural interests as well as protecting/restoring habitats in the sustainable sites category.

GPRS 2011 also doesn't help promote cycling and transportation efficiency as well as reducing vehicle distances traveled. Although both LEED v4 and v4.1 encourage cycling by providing bicycle racks in the project, they have different standards/requirements to achieve the credit. The reduced parking footprint credit in LEED v4.1 provides more methods of implementation within the project to achieve the point assigned to this credit (i.e. eliminating off-street parking, unbundling parking, and providing assigned parking spots for carpooling). The major difference between LEED v4 and v4.1 in this category lies in the green/electric vehicle credit, since LEED v4.1 addresses electric vehicles specifically which require that charging infrastructures be present for on-site parking.

\section{2) Sustainable Sites}

LEED addresses site assessment, open space, rainwater management, heat island reduction, and light pollution reduction while GPRS 2011 does not. Construction pollution prevention is mandatory in LEED whereas it is a regular credit in GPRS 2011. GPRS 2011 caters to remote sites by presenting a suitable method for connecting it with the nearest urban area. Surrounding density and diverse uses are addressed in the location and transportation credit in LEED and in the sustainable sites category in GPRS 2016 which encourages the development in areas with existing infrastructure. Furthermore, GPRS 2011 and 2016 accredit points for demonstrating suitable strategies for conserving/protecting historic and cultural interests that are part of/or nearby the site, as presented in Table 2. Meanwhile, LEED v2009 addresses the significance of respecting sites with historical or cultural interests in the site development credit in which disturbance to Greenfield sites (cultural and historic sites) should be limited. The building reuse credits in the materials and resources category of LEED also encourages protecting and conserving cultural resources and historic buildings.

\section{3) Water Efficiency}

GPRS 2011 focuses on the water category which is the main priority in the Egyptian rating system. It addresses several credits which are not addressed by LEED such as water feature efficiency, water leakage detection, efficient water use during construction, wastewater management, and sanitary used pipes, as presented in Table 2. LEED v2009 differs greatly from its more recent versions as water metering and cooling towers are not a requirement for achieving points. On the other hand, it addresses wastewater management unlike LEED v4 and v4. 1 in the innovative wastewater technologies credit.

\section{4) Energy Efficiency}

LEED (v4 and v4.1) prioritizes energy efficiency with $30 \%$ of the viable credits achievable. There are several credit weighting differences between LEED v2009 and the later versions (LEED v4 and v4.1). Although both systems address similar issues such as optimization of energy performance, incorporation of renewable energy, and enhanced refrigerant management, however, they address several different issues and prioritize them differently, as presented in Table 2.

\section{5) Materials and Resources}

LEED credits regarding materials and resources focus on the lifecycle of the material, as presented in Table 2. The credit weighting of several credits differ in LEED v2009 compared to LEED v4 and v4.1. It is mandatory to eliminate any exposure to toxic materials in GPRS 2011 and is not addressed in LEED BD+C: New Constructions, however, it is mandatory for LEED BD+C: Healthcare.

\section{6) Indoor Environmental Quality (IEQ)}

LEED addresses several issues regarding the indoor environmental quality, however, it does not address the 
importance of controlling legionella and other health risks as opposed to GPRS. The acoustic performance credit is not addressed in LEED v2009 whereas it is categorized as a credit in both LEED v4 and v4.1, as presented in Table 2. It is also a mandatory credit for LEED v2009 BD+C: Schools. The requirements of several credits in LEED v4.1 differ slightly from those of LEED v4.

\section{7) Management}

Although LEED doesn't have a management category, it is mandatory to present an early analysis of the interrelationships among systems in the integrative process credit in LEED v4 and v4.1. GPRS addresses issues starting from planning in the predesign stage up until the demolition stage. It also includes several credits which cover several aspects of operating the building, as presented in Table 2 .

\section{8) Innovation}

Innovation is a bonus category in GPRS whereas it is a main category in LEED BD+C. In GPRS, the innovation credits aim to achieve designs which reflect the national and regional cultural heritage while taking into account environmental performance and encouraging innovation. Likewise, this credit in LEED aims to encourage projects to achieve exceptional or innovative results. A credit can also be achieved when a LEED accredited professional participates in the project.

\section{9) Regional Priority}

Regional priority is addressed in LEED and not GPRS. It provides an incentive for achieving credits which address environmental, social, and public health priorities related to the geographic location of the project.

\section{Table 2 Category Contents for LEED \& GPRS}

\begin{tabular}{|c|c|c|c|c|c|}
\hline ISSUES & $\begin{array}{l}\text { LEED BD+C } \\
\text { v2009 }\end{array}$ & $\begin{array}{l}\text { LEED BD+C } \\
\text { v4 }\end{array}$ & $\begin{array}{l}\text { LEED BD+C } \\
\text { v4.1 }\end{array}$ & $\begin{array}{c}\text { GPRS } \\
2011\end{array}$ & $\begin{array}{c}\text { GPRS } \\
2016\end{array}$ \\
\hline \multicolumn{6}{|l|}{ LOCATION \& TRANSPORTATION } \\
\hline LEED for neighborhood development location & - & $\sqrt{ }$ & $\sqrt{ }$ & - & - \\
\hline Sensitive land protection & $\sqrt{ }$ & $\sqrt{ }$ & $\sqrt{ }$ & - & $\sqrt{ }$ \\
\hline High priority site/site selection & $\sqrt{ }$ & $\sqrt{ }$ & $\sqrt{ }$ & $\sqrt{ }$ & $\sqrt{ }$ \\
\hline Surrounding density and diverse uses & $\sqrt{ }$ & $\sqrt{ }$ & $\sqrt{ }$ & $\sqrt{ }$ & $\sqrt{ }$ \\
\hline Access to quality transit & $\sqrt{ }$ & $\sqrt{ }$ & $\sqrt{ }$ & $\sqrt{ }$ & $\sqrt{ }$ \\
\hline Bicycle facilities & $\sqrt{ }$ & $\sqrt{ }$ & $\sqrt{ }$ & - & $\sqrt{ }$ \\
\hline Reduced parking footprint & $\sqrt{ }$ & $\sqrt{ }$ & $\sqrt{ }$ & - & - \\
\hline Green vehicles & $\sqrt{ }$ & $\sqrt{ }$ & $\sqrt{ }$ & $\sqrt{ }$ & - \\
\hline \multicolumn{6}{|l|}{ SUSTAINABLE SITES } \\
\hline Construction pollution prevention & Mandatory & Mandatory & Mandatory & $\sqrt{ }$ & - \\
\hline Project design and implementation plan & - & $\sqrt{ }$ & $\sqrt{ }$ & Mandatory & $\sqrt{ }$ \\
\hline Site assessment & - & $\sqrt{ }$ & $\sqrt{ }$ & - & $\sqrt{ }$ \\
\hline Catering for remote sites & - & - & - & $\sqrt{ }$ & - \\
\hline Protect or restore habitat & $\sqrt{ }$ & $\sqrt{ }$ & $\sqrt{ }$ & $\sqrt{ }$ & $\sqrt{ }$ \\
\hline Respect for sites of historic or cultural interest & $\sqrt{ }$ & $\sqrt{ }$ & $\sqrt{ }$ & $\sqrt{ }$ & $\sqrt{ }$ \\
\hline Open space & $\sqrt{ }$ & $\sqrt{ }$ & $\sqrt{ }$ & - & - \\
\hline Rainwater management & $\sqrt{ }$ & $\sqrt{ }$ & $\sqrt{ }$ & - & $\sqrt{ }$ \\
\hline Heat island reduction & $\sqrt{ }$ & $\sqrt{ }$ & $\sqrt{ }$ & - & $\sqrt{ }$ \\
\hline Light pollution reduction & $\sqrt{ }$ & $\sqrt{ }$ & $\sqrt{ }$ & - & - \\
\hline \multicolumn{6}{|l|}{ WATER EFFICIENCY } \\
\hline Outdoor water use reduction & $\sqrt{ }$ & Mandatory & Mandatory & $\sqrt{ }$ & $\sqrt{ }$ \\
\hline Indoor water use reduction & Mandatory & Mandatory & Mandatory & $\sqrt{ }$ & $\sqrt{ }$ \\
\hline Building level water metering & - & $\sqrt{ }$ & $\sqrt{ }$ & Mandatory & $\sqrt{ }$ \\
\hline Cooling tower water use & - & $\sqrt{ }$ & $\sqrt{ }$ & $\sqrt{ }$ & - \\
\hline Water metering & - & $\sqrt{ }$ & $\sqrt{ }$ & Mandatory & $\sqrt{ }$ \\
\hline Water feature efficiency & $\sqrt{ }$ & $\sqrt{ }$ & $\sqrt{ }$ & $\sqrt{ }$ & $\sqrt{ }$ \\
\hline Water leakage detection & - & - & - & $\sqrt{ }$ & $\sqrt{ }$ \\
\hline Efficient water use during construction & - & - & - & $\sqrt{ }$ & - \\
\hline Waste water management & $\sqrt{ }$ & - & - & $\sqrt{ }$ & $\sqrt{ }$ \\
\hline Sanitary used pipes & - & - & - & $\sqrt{ }$ & - \\
\hline \multicolumn{6}{|l|}{ ENERGY EFFICIENCY } \\
\hline Fundamental commissioning and verification & Mandatory & Mandatory & Mandatory & - & - \\
\hline Minimum energy performance & Mandatory & Mandatory & Mandatory & Mandatory & - \\
\hline Ozone depletion avoidance & Mandatory & Mandatory & Mandatory & Mandatory & - \\
\hline Building level energy metering & $\sqrt{ }$ & Mandatory & Mandatory & Mandatory & - \\
\hline $\begin{array}{l}\text { Improve energy efficiency (optimize energy } \\
\text { performance) }\end{array}$ & $\sqrt{ }$ & $\sqrt{ }$ & $\sqrt{ }$ & $\sqrt{ }$ & $\sqrt{ }$ \\
\hline Energy efficient appliances & - & - & - & $\sqrt{ }$ & $\sqrt{ }$ \\
\hline Enhanced commissioning & $\sqrt{ }$ & $\sqrt{ }$ & $\sqrt{ }$ & - & - \\
\hline Passive external heat gain/loss reduction & - & - & - & $\sqrt{ }$ & $\sqrt{ }$ \\
\hline Vertical transportation systems & - & - & - & $\sqrt{ }$ & $\sqrt{ }$ \\
\hline Peak load reduction & - & - & - & $\sqrt{ }$ & - \\
\hline Advanced energy metering & - & $\sqrt{ }$ & $\sqrt{ }$ & - & - \\
\hline Demand response & - & $\sqrt{ }$ & $\sqrt{ }$ & - & - \\
\hline Renewable energy sources/production & $\sqrt{ }$ & $\sqrt{ }$ & $\sqrt{ }$ & $\sqrt{ }$ & $\sqrt{ }$ \\
\hline Green power and carbon offsets & $\sqrt{ }$ & $\sqrt{ }$ & $\sqrt{ }$ & - & $\sqrt{ }$ \\
\hline
\end{tabular}




\begin{tabular}{|c|c|c|c|c|c|}
\hline Enhanced refrigerant management & $\sqrt{ }$ & $\sqrt{ }$ & $\sqrt{ }$ & $\sqrt{ }$ & $\sqrt{ }$ \\
\hline Operation and maintenance & - & - & - & $\sqrt{ }$ & - \\
\hline Energy and carbon inventories & - & - & - & $\sqrt{ }$ & - \\
\hline \multicolumn{6}{|l|}{ MATERIALS \& RESOURCES } \\
\hline Storage and collection of recyclables & Mandatory & Mandatory & Mandatory & - & $\sqrt{ }$ \\
\hline Construction and demolition waste management planning & $\sqrt{ }$ & Mandatory & Mandatory & - & - \\
\hline Presentation of a Schedule of Principal Project Materials & - & - & - & Mandatory & - \\
\hline Elimination of exposure to hazardous/toxic materials & $\sqrt{ }$ & $\sqrt{ }$ & $\sqrt{ }$ & Mandatory & $\sqrt{ }$ \\
\hline Building life-cycle impact reduction (reuse of products) & $\sqrt{ }$ & $\sqrt{ }$ & $\sqrt{ }$ & $\sqrt{ }$ & $\sqrt{ }$ \\
\hline Recycled materials & $\sqrt{ }$ & $\sqrt{ }$ & $\sqrt{ }$ & $\sqrt{ }$ & $\sqrt{ }$ \\
\hline Environmental product declarations & - & $\sqrt{ }$ & $\sqrt{ }$ & - & - \\
\hline Sourcing of raw materials & $\sqrt{ }$ & $\sqrt{ }$ & $\sqrt{ }$ & - & - \\
\hline Material ingredients & - & $\sqrt{ }$ & $\sqrt{ }$ & - & $\sqrt{ }$ \\
\hline Regionally procured materials & $\sqrt{ }$ & - & - & $\sqrt{ }$ & $\sqrt{ }$ \\
\hline Materials fabricated on site & - & - & - & $\sqrt{ }$ & $\sqrt{ }$ \\
\hline Use of readily renewable materials & $\sqrt{ }$ & - & - & $\sqrt{ }$ & $\sqrt{ }$ \\
\hline Use of lightweight materials & - & - & - & $\sqrt{ }$ & - \\
\hline Use of higher durability materials & - & - & - & $\sqrt{ }$ & $\sqrt{ }$ \\
\hline Use of prefabricated and readily available elements & - & - & - & $\sqrt{ }$ & $\sqrt{ }$ \\
\hline \multicolumn{6}{|l|}{ INDOOR ENVIRONMENTAL QUALITY } \\
\hline Minimum indoor air quality performance & Mandatory & Mandatory & Mandatory & Mandatory & $\sqrt{ }$ \\
\hline Tobacco smoke control & Mandatory & Mandatory & Mandatory & Mandatory & $\sqrt{ }$ \\
\hline Enhanced indoor air quality strategies & $\sqrt{ }$ & $\sqrt{ }$ & $\sqrt{ }$ & - & $\sqrt{ }$ \\
\hline Control of legionella, other health risks, and pollutants & $\sqrt{ }$ & - & - & Mandatory & - \\
\hline Low-emitting materials & $\sqrt{ }$ & $\sqrt{ }$ & $\sqrt{ }$ & $\sqrt{ }$ & - \\
\hline Construction indoor air quality management plan & $\sqrt{ }$ & $\sqrt{ }$ & $\sqrt{ }$ & - & - \\
\hline Indoor air quality assessment & $\sqrt{ }$ & $\sqrt{ }$ & $\sqrt{ }$ & $\sqrt{ }$ & $\sqrt{ }$ \\
\hline Thermal comfort & $\sqrt{ }$ & $\sqrt{ }$ & $\sqrt{ }$ & $\sqrt{ }$ & $\sqrt{ }$ \\
\hline Interior lighting & $\sqrt{ }$ & $\sqrt{ }$ & $\sqrt{ }$ & $\sqrt{ }$ & $\sqrt{ }$ \\
\hline Daylight & $\sqrt{ }$ & $\sqrt{ }$ & $\sqrt{ }$ & $\sqrt{ }$ & $\sqrt{ }$ \\
\hline Quality views & $\sqrt{ }$ & $\sqrt{ }$ & $\sqrt{ }$ & - & $\sqrt{ }$ \\
\hline Acoustic performance & - & $\sqrt{ }$ & $\sqrt{ }$ & $\sqrt{ }$ & $\sqrt{ }$ \\
\hline \multicolumn{6}{|l|}{ MANAGEMENT } \\
\hline Integrated Plan and Method Statement for site operations & - & $\sqrt{ }$ & $\sqrt{ }$ & Mandatory & $\sqrt{ }$ \\
\hline Compliance with national Health \& Safety regulations & - & $\sqrt{ }$ & $\sqrt{ }$ & Mandatory & - \\
\hline Method statement for demolition work. & - & Mandatory & Mandatory & Mandatory & - \\
\hline Containers for site waste & $\sqrt{ }$ & $\sqrt{ }$ & $\sqrt{ }$ & $\sqrt{ }$ & $\sqrt{ }$ \\
\hline Waste recycling on site & $\sqrt{ }$ & $\sqrt{ }$ & $\sqrt{ }$ & $\sqrt{ }$ & $\sqrt{ }$ \\
\hline Access for lorries and equipment & $\sqrt{ }$ & $\sqrt{ }$ & $\sqrt{ }$ & $\sqrt{ }$ & - \\
\hline Identified and separated storage areas & $\sqrt{ }$ & $\sqrt{ }$ & $\sqrt{ }$ & $\sqrt{ }$ & - \\
\hline Project waste management plan & $\sqrt{ }$ & $\sqrt{ }$ & $\sqrt{ }$ & $\sqrt{ }$ & $\sqrt{ }$ \\
\hline Engaging a company for recycling \& disposal & $\sqrt{ }$ & $\sqrt{ }$ & $\sqrt{ }$ & $\sqrt{ }$ & $\sqrt{ }$ \\
\hline Protecting water sources from pollution & $\sqrt{ }$ & $\sqrt{ }$ & $\sqrt{ }$ & $\sqrt{ }$ & - \\
\hline Waste from mixing equipment & - & $\sqrt{ }$ & $\sqrt{ }$ & $\sqrt{ }$ & $\sqrt{ }$ \\
\hline Control of emissions and pollutants & $\sqrt{ }$ & $\sqrt{ }$ & $\sqrt{ }$ & $\sqrt{ }$ & - \\
\hline Providing a building user guide & - & - & - & $\sqrt{ }$ & $\sqrt{ }$ \\
\hline Providing a maintenance schedule & - & - & - & $\sqrt{ }$ & $\sqrt{ }$ \\
\hline
\end{tabular}

Table 3 Sustainability Pillars of LEED \& GPRS

\begin{tabular}{|c|c|c|c|c|c|c|}
\hline \multicolumn{2}{|c|}{ ISSUES } & $\begin{array}{l}\text { LEED BD+C } \\
\text { v2009 }\end{array}$ & $\begin{array}{l}\text { LEED BD+C } \\
\text { v4 }\end{array}$ & $\begin{array}{l}\text { LEED BD+C } \\
\text { v4.1 }\end{array}$ & $\begin{array}{c}\text { GPRS } \\
2011\end{array}$ & $\begin{array}{c}\text { GPRS } \\
2016\end{array}$ \\
\hline \multirow{10}{*}{ 畜 } & Reduce GHG emission & $\sqrt{ }$ & $\sqrt{ }$ & $\sqrt{ }$ & $\sqrt{ }$ & $\sqrt{ }$ \\
\hline & Reduce stratospheric ozone depletion & $\sqrt{ }$ & $\sqrt{ }$ & $\sqrt{ }$ & $\sqrt{ }$ & $\sqrt{ }$ \\
\hline & Mitigate the impact of on-site ecology & $\sqrt{ }$ & $\sqrt{ }$ & $\sqrt{ }$ & $\sqrt{ }$ & $\sqrt{ }$ \\
\hline & Minimize waste production & $\sqrt{ }$ & $\sqrt{ }$ & $\sqrt{ }$ & $\sqrt{ }$ & $\sqrt{ }$ \\
\hline & Minimize primary energy consumption & $\sqrt{ }$ & $\sqrt{ }$ & $\sqrt{ }$ & $\sqrt{ }$ & $\sqrt{ }$ \\
\hline & Limit raw materials use & $\sqrt{ }$ & $\sqrt{ }$ & $\sqrt{ }$ & $\sqrt{ }$ & $\sqrt{ }$ \\
\hline & Minimize water consumption & $\sqrt{ }$ & $\sqrt{ }$ & $\sqrt{ }$ & $\sqrt{ }$ & $\sqrt{ }$ \\
\hline & Minimize land consumption & $\sqrt{ }$ & $\sqrt{ }$ & $\sqrt{ }$ & $\sqrt{ }$ & $\sqrt{ }$ \\
\hline & Improve environmental management & $\sqrt{ }$ & $\sqrt{ }$ & $\sqrt{ }$ & $\sqrt{ }$ & $\sqrt{ }$ \\
\hline & Limit climatological risk & $\sqrt{ }$ & $\sqrt{ }$ & $\sqrt{ }$ & - & $\sqrt{ }$ \\
\hline \multirow{8}{*}{ ঠ్ } & Visual comfort & $\sqrt{ }$ & $\sqrt{ }$ & $\sqrt{ }$ & $\sqrt{ }$ & $\sqrt{ }$ \\
\hline & Thermal comfort & $\sqrt{ }$ & $\sqrt{ }$ & $\sqrt{ }$ & $\sqrt{ }$ & $\sqrt{ }$ \\
\hline & Acoustic comfort & - & $\sqrt{ }$ & $\sqrt{ }$ & $\sqrt{ }$ & $\sqrt{ }$ \\
\hline & IAQ & $\sqrt{ }$ & $\sqrt{ }$ & $\sqrt{ }$ & $\sqrt{ }$ & $\sqrt{ }$ \\
\hline & Outdoor comfort & - & $\sqrt{ }$ & $\sqrt{ }$ & - & - \\
\hline & Reduce exposure to hazardous substances & $\sqrt{ }$ & $\sqrt{ }$ & $\sqrt{ }$ & $\sqrt{ }$ & $\sqrt{ }$ \\
\hline & Provide health targets & - & $\sqrt{ }$ & $\sqrt{ }$ & $\sqrt{ }$ & $\sqrt{ }$ \\
\hline & Public services & $\sqrt{ }$ & $\sqrt{ }$ & $\sqrt{ }$ & - & $\sqrt{ }$ \\
\hline
\end{tabular}




\begin{tabular}{|c|c|c|c|c|c|c|}
\hline & Public transport & $\sqrt{ }$ & $\sqrt{ }$ & $\sqrt{ }$ & $\sqrt{ }$ & $\sqrt{ }$ \\
\hline & Pedestrian network & $\sqrt{ }$ & $\sqrt{ }$ & $\sqrt{ }$ & $\sqrt{ }$ & $\sqrt{ }$ \\
\hline & Bicycling network & $\sqrt{ }$ & $\sqrt{ }$ & $\sqrt{ }$ & - & $\sqrt{ }$ \\
\hline & Carpooling & $\sqrt{ }$ & $\sqrt{ }$ & $\sqrt{ }$ & - & - \\
\hline & Participatory framework & $\sqrt{ }$ & $\sqrt{ }$ & $\sqrt{ }$ & $\sqrt{ }$ & $\sqrt{ }$ \\
\hline & Social \& ethical responsibility & - & $\sqrt{ }$ & $\sqrt{ }$ & $\sqrt{ }$ & $\sqrt{ }$ \\
\hline & Sensitivity to the local community & $\sqrt{ }$ & $\sqrt{ }$ & $\sqrt{ }$ & $\sqrt{ }$ & $\sqrt{ }$ \\
\hline & Building aesthetics & - & - & - & - & - \\
\hline & Heritage \& cultural & $\sqrt{ }$ & $\sqrt{ }$ & $\sqrt{ }$ & $\sqrt{ }$ & $\sqrt{ }$ \\
\hline \multirow{10}{*}{ 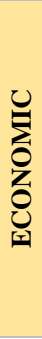 } & Reduce LCC & $\sqrt{ }$ & $\sqrt{ }$ & $\sqrt{ }$ & - & $\sqrt{ }$ \\
\hline & Preserve the quality and value of the site & $\sqrt{ }$ & $\sqrt{ }$ & $\sqrt{ }$ & $\sqrt{ }$ & $\sqrt{ }$ \\
\hline & Building adaptability & $\sqrt{ }$ & $\sqrt{ }$ & $\sqrt{ }$ & - & - \\
\hline & Ease of maintenance & $\sqrt{ }$ & $\sqrt{ }$ & $\sqrt{ }$ & $\sqrt{ }$ & $\sqrt{ }$ \\
\hline & Reduce construction and financing costs & $\sqrt{ }$ & $\sqrt{ }$ & $\sqrt{ }$ & - & $\sqrt{ }$ \\
\hline & Improve construction and management standards & $\sqrt{ }$ & $\sqrt{ }$ & $\sqrt{ }$ & $\sqrt{ }$ & $\sqrt{ }$ \\
\hline & Locally-sourced materials & $\sqrt{ }$ & $\sqrt{ }$ & $\sqrt{ }$ & $\sqrt{ }$ & $\sqrt{ }$ \\
\hline & Improve building user productivity & $\sqrt{ }$ & $\sqrt{ }$ & $\sqrt{ }$ & $\sqrt{ }$ & $\sqrt{ }$ \\
\hline & Innovation & $\sqrt{ }$ & $\sqrt{ }$ & $\sqrt{ }$ & $\sqrt{ }$ & $\sqrt{ }$ \\
\hline & Support of national economy & - & - & $\sqrt{ }$ & $\sqrt{ }$ & - \\
\hline
\end{tabular}

\section{Sustainability Pillars}

Table 3 presents a comparison of the three sustainability pillars in the selected rating systems.

\section{E. Validity}

LEED BD+C certifications do not expire. However, LEED recertification is valid for three years. Recertification is available for occupied projects that have previously achieved certification under LEED. However, LEED projects certified under $\mathrm{BD}+\mathrm{C}$ and $\mathrm{ID}+\mathrm{C}$ do not require recertification. Table 4 presents a comparison of the validity of the certification achieved by each of the selected systems.

\section{F. Adaptability}

LEED can be applied in different countries other than its country of origin. Several versions of LEED have also been developed for specific countries, such as LEED - Canada and LEED - India. On the other hand, GPRS is a national rating system developed specifically for Egypt. Table 4 presents the adaptability of the selected systems.

\section{G. Lifecycle Stages Coverage}

The stages at which projects can be assessed using LEED and GPRS are shown in Table 4.

\section{H. Cost Assessment}

The cost of assessment in LEED [20] differs according to whether the applicant for certification is a member or not as well as the gross floor area (excluding parking) of the project. Table 5 presents a comparison of the cost of certification by each of the selected systems.

Table 4 Aspects of Comparison for LEED \& GPRS

\begin{tabular}{|c|c|c|c|}
\hline CATEGORIES & LEED BD+C v2009 LEED BD+C v4 & LEED BD+C v4.1 & GPRS 2011 \\
\hline \multicolumn{4}{|c|}{$\begin{array}{l}\text { Validity } \\
\end{array}$} \\
\hline Validity & Indefinite & & 5 years \\
\hline \multicolumn{4}{|c|}{ Adaptability } \\
\hline Local Applicability & $\sqrt{ }$ & & $\sqrt{ }$ \\
\hline International Applicability & $\sqrt{ }$ & & - \\
\hline Flexibility & $\sqrt{ }$ & & - \\
\hline Climate Concerns & $\sqrt{ }$ & & - \\
\hline Cultural Values and Heritage & - & & $\sqrt{ }$ \\
\hline \multicolumn{4}{|c|}{ Lifecycle Stages Coverage } \\
\hline Pre-design/Site Selection & - & & - \\
\hline Design/Construction & $\sqrt{ }$ & & $\sqrt{ }$ \\
\hline Core and Shell & $\sqrt{ }$ & & - \\
\hline Post Construction & $\sqrt{ }$ & & - \\
\hline Refurbishment & - & & - \\
\hline Operation/Maintenance & - & & - \\
\hline
\end{tabular}

Table 5 Cost Assessment for LEED \& GPRS

\begin{tabular}{|c|c|c|c|c|}
\hline CATEGORIES & LEED BD+C v4 & LEED BD+C v4.1 & GPRS 2011 & GPRS 2016 \\
\hline Registration/Interim Certificate & $\begin{array}{r}\mathrm{N} \\
\text { Nor }\end{array}$ & $\begin{array}{l}, 200 \\
\$ 1,500\end{array}$ & \multicolumn{2}{|c|}{ Not stated } \\
\hline $\begin{array}{l}\text { Pre-certification } \\
\text { (per building) }\end{array}$ & $\begin{array}{r}1 \\
\text { Nor }\end{array}$ & $\begin{array}{l}, 000 \\
\$ 5,000\end{array}$ & \multicolumn{2}{|c|}{$\mathrm{n} / \mathrm{a}$} \\
\hline Certification & $\begin{array}{r}\text { Base } \\
(\mathrm{e})\end{array}$ & $\begin{array}{l}\text { oor area } \\
\text { king) }\end{array}$ & \multicolumn{2}{|r|}{$\mathrm{n} / \mathrm{a}$} \\
\hline
\end{tabular}




\section{EGYPTIAN BUILDING STANDARDS}

\section{A. Unified Building Law (Law No. 119 - 2008)}

Law no.119 for the year 2008 [21], mostly known as the "Unified Building Law" was issued by a presidential decree and approved by the house of parliament. The law was issued in order to regulate the building process nationally. It was decreed in an amendment and in integration with previous laws while eliminating other laws or parts of them. The Unified Building Law addresses a variety of issues relating to regulations about national planning, regional planning, city planning, land divisions, unplanned zones, and special zones. The law covers a large number of issues. However, it focuses on the administrative and juridical aspects of the construction process of construction.

The version of the Unified Building Law analyzed is the 2015 version. The following presents the most significant articles of the Unified Building Law (Law no. 119 - 2008) which contradict and/or support the achievement of green architecture in Egypt.

- Article 2 defines a strategic plan as the plan for future urban development, however, it doesn't represent the framework for the entire country and its general vision for sustainability. The GPRS site selection credits include a credit for the compatibility of the project with the National Development Plan to attain maximum benefit from the existing infrastructure, protect green areas, and preserve natural resources.

- Article 15 emphasizes that each region must have its own strategic and detailed plan in order to develop its own regulations. However, it fails to mention the significance of the local climate and culture in developing regulations or strategic plans. It also stresses the significance of attaining natural lighting, ventilation, and maintaining the architectural and urban identity, thereby inadvertently following a green concept. By regulating the height to 1.5 times the width of the street with a maximum of 36 meters, it disregards many health and environmental concerns.

\section{B. The Executive Appendix for the Unified Building Law}

The Executive Appendix for the Unified Building Law [22] was published in April 2009. It is a descriptive appendix for the Unified Building Law. It provides further descriptions of the articles in the main law.

The version of the Executive Appendix for the Unified Building Law analyzed is the 2015 version. The following presents the most significant articles of the Executive Appendix for the Unified Building Law (Law no. 119 - 2008) which contradict and/or support the achievement of green architecture in Egypt.

- Article 23 states that future strategic plans must include the environmental requirements and the treatment of the sources of pollution in the region. Reducing pollution from construction activities is a prerequisite of LEED and is a regular credit for GPRS. LEED also accredits points for minimizing light pollution by reducing the impact of lighting on nocturnal environments.
- Article 34 states that the roads surrounding an administrative region must be thoroughly analyzed as well as the pedestrian paths. This article correlates with the GPRS credit requirements for accessibility. However, it doesn't underline the necessity of access to public transport or alternative methods of transportation as required in LEED and GPRS 2016.

- Article 52 states that it is essential to ensure sufficient lighting and ventilation in each residential unit as well as the importance of protecting/maintaining the surrounding natural environment, and providing enough parking for the project. However, it doesn't ensure natural lighting and ventilation in other types of projects including office buildings.

- Article 93 specifies that the minimum clear height of any floor is 2.7 meters in any living space and 2.3 meters in corridors and service areas. Sticking to the minimum height may contradict several indoor environmental quality credits in terms of sufficient natural light and cross ventilation reaching the entirety of the architectural spaces. The maximum height of a building is calculated by 1.5 times the width of the main street of the building as stated in article 15 of the Unified Building Law while the minimum clear height of an architectural space is 2.7 meters. As a result, contractors and owners tend to execute their projects using the minimum clear height in order to have more floors and units within the same total building height for maximum profit.

- Article 94 specifies the minimum floor area of residential spaces. Whereas, there aren't any guidelines for the minimum dimensions of administrative spaces. As a result, the administrative spaces designed and constructed may not provide a suitable working environment.

- Article 96 states that all architectural spaces in residential buildings must have one window at least. The openings must be clear and not blocked in order to provide ventilation and lighting to the space. It also specifies the minimum surface area of windows based on the type of space they are in. However, it states that administrative spaces aren't required to have windows and can be artificially ventilated and lit instead, although office buildings are used for long hours and must provide a healthy working environment for their employees. Therefore, contradicting the mandatory requirements for LEED or GPRS for minimum ventilation and indoor air quality requirements.

- Article 98 states that some architectural spaces can have their main windows facing a court. Therefore, courts must abide by several regulations to ensure airflow and sunlight to the space. The court dimensions are affected by the total height of the building. As the height of the building increases the court dimensions must increase in order to ensure maximum reach of air and light to the lower floors through the court. However, in reality, contractors do not abide by those regulations which affect indoor environmental quality.

- Article 99 also provides further dimension restrictions for the openings of recessed elements in pocket courts to ensure adequate natural lighting and ventilation. The depth of the recession must not exceed half its width and the 
window must face the recession directly. Such pocket courts are usually $1.0 \times 1.0 \mathrm{~m}$ ducts that don't provide healthy ventilation nor adequate lighting.

- Articles 101 and 102 state that courts must not include any structures which may obstruct/block the natural light and ventilation from the architectural spaces.

- Article 106 states that fire regulations are required in office buildings that exceed $200 \mathrm{~m}^{2}$ in total area and 4 meters in height. Installing fire suppression systems is not a requirement for LEED, however, any fire suppression system installed cannot contain ozone-depleting substances which contribute to climate change. It is also mandatory for fire suppression agents in projects assessed by GPRS to have an Ozone Depletion Potential near zero.

- Article 108 states that buildings are required to provide a parking area for visitors/residents. However, there is no mention of bicycle racks in Unified Building Law and its Executive Appendix.

In conclusion, the Unified Building Law and its' Executive Appendix don't include articles which obstruct the applicability of either GPRS or LEED. The minimum requirements in the articles of the Unified Building Law and its Executive Appendix don't provide suitable indoor environments if the contractors rely on meeting only the minimum requirements for financial gain. It is evident that they don't take green architectural concepts into account. Therefore, their articles need to be revised and the minimum requirements should meet the universal green standards.

\section{CASE STUDIES}

The case studies were chosen based on the type of building and the type of LEED certification achieved. This study specifically analyzes Egyptian office buildings with LEED BD+C: NC v2009 certifications. Hence, the case studies selected are as follows Dar Al-Handasah New Premises [23] [24], Crédit Agricole Head Offices in New Cairo [25] [26], Outsourcing Service Building - MB4 [27] [28], and EMEC Headquarters [29] [30].

The case studies were reevaluated using the second edition of GPRS in order to determine its achievable level of certification. The requirements for their LEED certification have contributed to the project achieving several points in GPRS 2016. Table 6 presents the estimated points achievable by the projects based on the information available.

\section{A. GPRS Assessment}

The requirements for each project to achieve a LEED certification have contributed to the projects achieving several points in GPRS 2016. The projects were analyzed in regards to the requirements of GPRS 2016 to determine its achievable level of certification.
MB4 Building and EMEC Headquarters are both eligible for 1 point in SS.01 credit as they were constructed in the bounds of the existing city, Maadi Technology Park and Fifth Settlement respectively. The vertical shading system installed on the Dar Al-Handasah Building exterior provides shade to around $75 \%$ of the building at over $50 \%$ of the total surface area. As a result, the project is eligible for 7 points in SS.06 credit. Credit Agricole is also eligible for 5 points for SS.06 credit since the plants used in the project's landscape were the plants which were originally found on the site prior to construction, in addition to the solar panels on the roof which also protect the building from the heat island effect.

EMEC Headquarters exterior is thermally insulated and has shaded glazing which reduces heat gain and the need for HVAC systems. Thus, it is eligible for 6 points in EE.02. For Dar Al-Handasah, 10 points are achievable in EE.03 credit due to the project's initiative to purchase $35 \%$ green power in addition to $1 \%$ on-site renewable energy. Whereas, EMEC Headquarters has photovoltaic solar panels which produce $4.4 \%$ of the building's annual energy use which does not meet the minimum percentage required to be awarded points. Crédit Agricole is eligible for 8 to 10 points for EE.05 by providing efficient lighting systems. The variation in achievable points depends on whether the lamp efficiency ranges are greater than $60 \mathrm{~lm} / \mathrm{W}$. The stairs and the elevators in Dar Al-Handasah Building are close and visible from the entrance of the project which makes the project eligible for 2 points. The stairs in Crédit Agricole are centralized and daylit which economize lift use. The remaining 4 points (EE.06) for both projects depend on the energy efficiency label of the elevators.

The $50 \%$ reduction in potable water use makes the MB4 Building eligible for 2 points in WE.02. Crédit Agricole can also achieve 2 out of the 4 points appointed to the waterefficient landscaping credit due to the incorporation of native plants in the project. However, the credit requires no use of potable water at all to achieve the remaining 2 points. Hence, it is not eligible for the remaining 2 points since it requires a dripping irrigation system. Crédit Agricole qualifies for 20 points in WE.03 since it presents a $40 \%$ reduction in potable water.

The distance of the regionally procured materials from the project is unknown. LEED v2009 accredits points based on the percentage of materials procured within $750 \mathrm{~km}$ from the project, however, GPRS 2016 MR.02 credit accredits points based on the distance traveled with a maximum of $500 \mathrm{~km}$. Hence, the points achievable are unknown. Although Dar AlHandasah incorporates $20 \%$ of recycled building materials, however, MR.03 requires a minimum of $25 \%$. Hence, the project was not eligible for the (MR.03) points available.

The additional credits appointed to the innovation and construction category are an estimation of the possible score which are determined by the GPRS committee. 


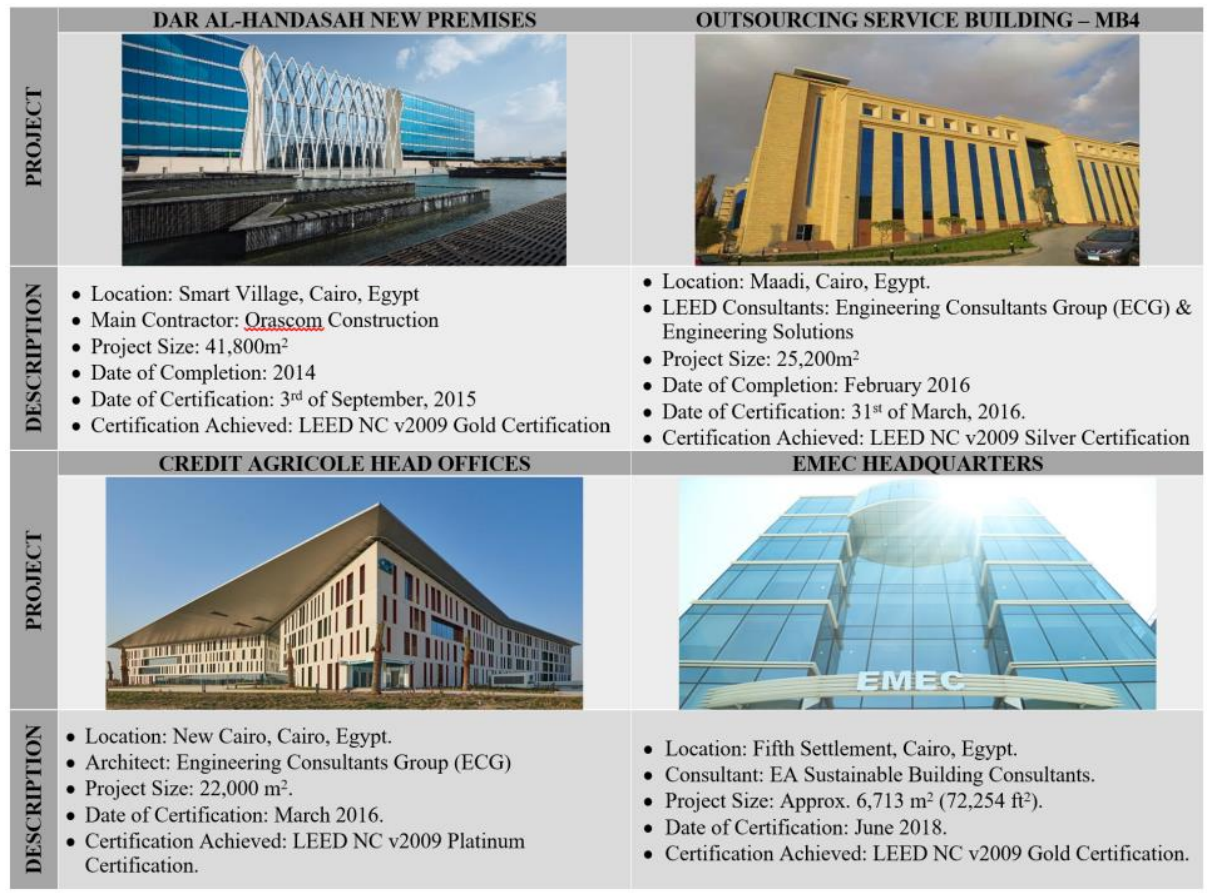

Figure 4 Egyptian LEED-certified Case Studies

Table 6 GPRS 2016 Credit Assessment for Egyptian Case Studies

\section{Category / Sub-category}

SS.01 Site Selection

SS.02 Community Services and Connectivity

SS.03 Public Transportation Access \& Pedestrian

Access

SS.04 Dedicated Bicycles Parking

SS.05 Storm/Rainwater Design (Quantity \&

Quality Control)

SS.06 Heat Island Effect (Green Space

Hardscape - Building)

2

EE.01 Energy Efficiency Improvement

EE.02 Passive External Heat Gain Reduction

EE.03 Renewable Energy Sources

EE.04 Energy Efficient HVAC Systems

EE.05 Efficient Artificial Lighting Systems

EE.06 Vertical Transportation

3

WE.01 Wastewater Reuse

WE.02 Water Efficient Landscaping

WE.03 Water Efficient Fixtures

WE.04 Metering and Leak Detection System

MR.01 Renewable Materials and Materials

Manufactured Using Renewable Energy

MR.02 Regionally Procured Materials \& Products

MR.03 Recycled/Reused Materials \& Materials

Manufactured On-Site Using Recycled Materials

MR.04 Reduction of Overall Material Use

MR.05 Alternative Building Systems with Low

Environmental Impact

MR.06 Environmentally - Friendly Sound \&

Thermal Insulation Materials

IQ.01 Enhance Ventilation Performance

IQ.02 Smoking Control

\begin{tabular}{c|c|c|c|c|c|c|}
\multicolumn{2}{c|}{ Dar Al-Handasah } & \multicolumn{2}{c}{ Crédit Agricole } & MB4 BUILDING & \multicolumn{2}{c|}{ EMEC Headquarters } \\
$\begin{array}{c}\text { Credits } \\
\text { Expected }\end{array}$ & $\begin{array}{c}\text { Evidence } \\
\text { Available }\end{array}$ & $\begin{array}{c}\text { Credits } \\
\text { Expected }\end{array}$ & $\begin{array}{c}\text { Evidence } \\
\text { Available }\end{array}$ Expected & $\begin{array}{c}\text { Evidence } \\
\text { Available }\end{array}$ & $\begin{array}{c}\text { Credits } \\
\text { Expected }\end{array}$ & $\begin{array}{c}\text { Evidence } \\
\text { Available }\end{array}$
\end{tabular}
SUSTAINABLE SITES

\begin{tabular}{|c|c|c|c|c|c|c|c|}
\hline 5 & $\sqrt{ }$ & 4 & $\sqrt{ }$ & 1 & $\sqrt{ }$ & 1 & $\sqrt{ }$ \\
\hline- & - & - & - & 4 & $\sqrt{ }$ & 4 & $\sqrt{ }$ \\
\hline 8 & $\sqrt{ }$ & 5 & $\sqrt{ }$ & 8 & $\sqrt{ }$ & 5 & $\sqrt{ }$ \\
\hline- & - & $3-4$ & $\sqrt{ }$ & 3 & $\sqrt{ }$ & 3 & $\sqrt{ }$ \\
\hline 4 & $\sqrt{ }$ & 2 & $\sqrt{ }$ & - & - & 2 & $\sqrt{ }$ \\
\hline 7 & $\sqrt{ }$ & 5 & $\sqrt{ }$ & 1 & $\sqrt{ }$ & 3 & $\sqrt{ }$
\end{tabular}

\section{ENERGY EFFICIENCY}

\begin{tabular}{c|c|c|c|c|c|c|c|}
\hline 4 & $\sqrt{ }$ & 10 & $\sqrt{ }$ & 2 & $\sqrt{ }$ & 2 & $\sqrt{ }$ \\
\hline 4 & $\sqrt{ }$ & 8 & $\sqrt{ }$ & 4 & $\sqrt{ }$ & 6 & $\sqrt{ }$ \\
\hline 10 & $\sqrt{ }$ & 10 & $\sqrt{ }$ & - & - & - & - \\
\hline $4-12$ & $\sqrt{ }$ & 12 & $\sqrt{ }$ & 12 & $\sqrt{ }$ & 12 & $\sqrt{ }$ \\
\hline 6 & $\sqrt{ }$ & $8-10$ & $\sqrt{ }$ & 8 & $\sqrt{ }$ & 8 & $\sqrt{ }$ \\
\hline $2-6$ & $\sqrt{ }$ & $2-6$ & $\sqrt{ }$ & $1-5$ & $\sqrt{ }$ & - & - \\
\multicolumn{7}{l}{ WATER EFFICIENCY } &
\end{tabular}

\begin{tabular}{c|c|c|c|c|c|c|c|}
\hline- & - & - & - & - & - & - & $\sqrt{ }$ \\
\hline 4 & $\sqrt{ }$ & 2 & $\sqrt{ }$ & 2 & $\sqrt{ }$ & 4 & $\sqrt{ }$
\end{tabular}

MATERIALS AND RESOURCES

\section{INDOOR ENVIRONMENTAL QUALITY}

\begin{tabular}{|c|c|c|c|c|}
\hline $4-6$ & $\sqrt{ }$ & 7 & $\sqrt{ }$ & 7 \\
\hline 2 & $\sqrt{ }$ & 2 & $\sqrt{ }$ & 2 \\
\hline
\end{tabular}




\begin{tabular}{|c|c|c|c|c|c|c|c|c|c|}
\hline & IQ.03 Thermal Comfort & 7 & $\sqrt{ }$ & 7 & $\sqrt{ }$ & 7 & $\sqrt{ }$ & 7 & $\sqrt{ }$ \\
\hline & IQ.04 Visual Comfort & 2 & $\sqrt{ }$ & 5 & $\sqrt{ }$ & 2 & $\sqrt{ }$ & 4 & $\sqrt{ }$ \\
\hline & IQ.05 Acoustic Comfort & - & - & - & - & - & - & - & - \\
\hline \multirow[t]{6}{*}{6} & \multicolumn{9}{|c|}{ MANAGEMENT PROTOCOLS } \\
\hline & MP.01 Building Information Modeling & - & - & - & - & - & - & - & - \\
\hline & MP.02 Life Cycle Assessment & 2 & $\sqrt{ }$ & 2 & $\sqrt{ }$ & 2 & $\sqrt{ }$ & 2 & $\sqrt{ }$ \\
\hline & MP.03 Sub Metering & 2 & $\sqrt{ }$ & 2 & $\sqrt{ }$ & 2 & $\sqrt{ }$ & 2 & $\sqrt{ }$ \\
\hline & MP.04 Building User Guide & - & - & - & - & - & - & - & - \\
\hline & MP.05 Solid Waste Management & 4 & $\sqrt{ }$ & 4 & $\sqrt{ }$ & 4 & $\sqrt{ }$ & 4 & $\sqrt{ }$ \\
\hline \multirow[t]{3}{*}{7} & \multicolumn{9}{|c|}{ CONSTRUCTION AND INNOVATION } \\
\hline & CI.01 Construction Site Practices & 2 & $\sqrt{ }$ & 3 & $\sqrt{ }$ & 3 & $\sqrt{ }$ & 3 & $\sqrt{ }$ \\
\hline & CI.02 Innovation & 2 & $\sqrt{ }$ & 3 & $\sqrt{ }$ & 1 & $\sqrt{ }$ & 3 & $\sqrt{ }$ \\
\hline
\end{tabular}

Table 7 GPRS 2016 Category Assessment for Egyptian Case Studies

\begin{tabular}{|c|c|c|c|c|c|c|c|c|c|c|}
\hline \multirow[b]{2}{*}{ CATEGORY } & \multirow[b]{2}{*}{$\begin{array}{l}\text { Max. } \\
\text { Score }\end{array}$} & \multirow{2}{*}{$\begin{array}{c}\text { Max. } \\
\text { Weight } \\
(\%)\end{array}$} & \multicolumn{2}{|c|}{ Dar Al-Handasah } & \multicolumn{2}{|c|}{ Crédit Agricole } & \multicolumn{2}{|c|}{ MB4 BUILDING } & \multicolumn{2}{|c|}{ EMEC Headquarters } \\
\hline & & & Score & $\begin{array}{l}\text { Weight } \\
(\%)\end{array}$ & Score & $\begin{array}{l}\text { Weight } \\
(\%)\end{array}$ & Score & $\begin{array}{c}\text { Weight } \\
(\%)\end{array}$ & Score & $\begin{array}{c}\text { Weight } \\
(\%)\end{array}$ \\
\hline Sustainable Sites (SS) & 40 & 10 & 24 & 6 & $20-21$ & $5-5.25$ & 17 & 4.25 & 18 & 4.5 \\
\hline Energy Efficiency (EE) & 60 & 30 & $30-42$ & $15-21$ & $50-56$ & $25-28$ & $27-31$ & $13.5-15.5$ & 28 & 14 \\
\hline Water Efficiency (WE) & 44 & 22 & 24 & 12 & 22 & 11 & 17 & 8.5 & 24 & 12 \\
\hline Materials and Resources (MR) & 28 & 14 & 4 & 2 & - & - & - & - & - & - \\
\hline $\begin{array}{l}\text { Indoor Environmental Quality } \\
\text { (IQ) }\end{array}$ & 28 & 14 & $15-17$ & $7.5-8.5$ & 21 & 10.5 & 18 & 9 & 20 & 10 \\
\hline Management Protocols (MP) & 18 & 10 & 8 & 4.5 & 8 & 4.5 & 8 & 4.5 & 8 & 4.5 \\
\hline $\begin{array}{l}\text { Construction and Innovation } \\
\text { (CI) }\end{array}$ & 6 & 5 & 4 & 3.5 & 6 & 5 & 4 & 3.5 & 6 & 5 \\
\hline TOTAL & 224 & 105 & $109-123$ & $50.5-57.5$ & $127-134$ & $61-64.25$ & $91-95$ & $43.25-45.25$ & 104 & 50 \\
\hline
\end{tabular}

\section{RESULTS}

The four Egyptian LEED-certified projects were reevaluated using GPRS 2016 to identify the achievable certification for each project in comparison to their LEED certifications. Dar Al-Handasah New Cairo Premises was awarded 62 points in total thereby achieving LEED: NC Gold certification while achieving a three pyramid certification for GPRS 2016. Crédit Agricole was awarded 81 points in total thereby achieving LEED: NC Platinum certification, while also achieving a three pyramid certification for GPRS 2016. Outsourcing Service Building - MB4 was also reevaluated and found to be eligible for a two pyramid certification for GPRS 2016 while achieving a LEED: NC Silver certification. Lastly, EMEC Headquarters is eligible for a three pyramid certification for GPRS 2016 while achieving a LEED: NC Gold certification with 66 points. In conclusion, projects with higher LEED certifications were also found to have higher GPRS 2016 scores, as presented in Figure 5.

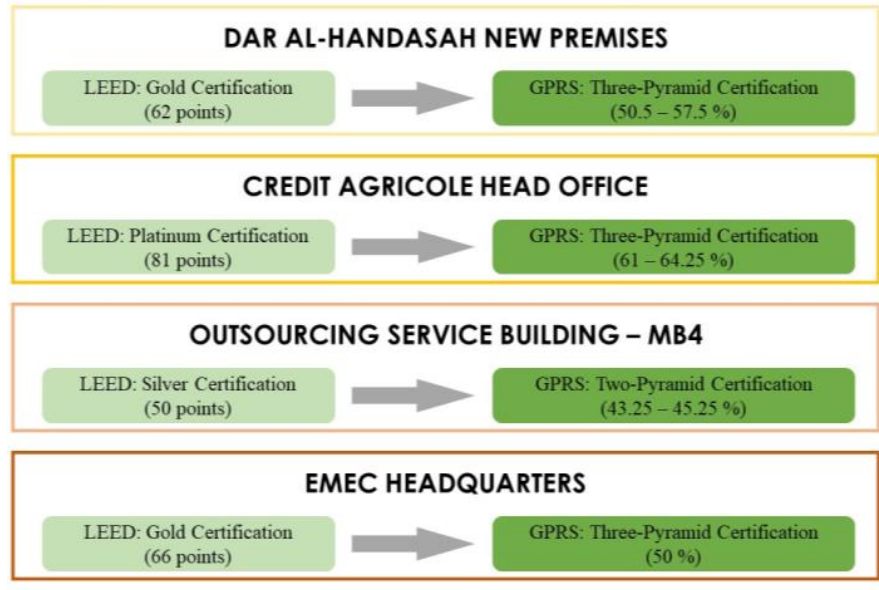

Figure 5 Case Study Certification Levels

\section{CONCLUSIONS}

The categories covered by the Egyptian and American GBRSs, GPRS (2011 and 2016) and LEED (v2009, v4, and v4.1) were compared and the aspects they emphasize were identified. Both rating systems address similar issues in the majority of their categories. However, GPRS addresses more issues than LEED in both the energy and water categories while also giving these categories the highest category weightings. GPRS lacked in comparison to LEED in terms of social issues such as outdoor comfort, public services, and carpooling.

The Unified Building Law No.119 for the year 2008 and its Executive Appendix released in 2009 by the Ministry of Housing were analyzed and several contradictions were found between them and the GBRSs analyzed. They permit building designs and procedures which don't align with the requirements of GPRS and LEED. They also don't reference GPRS or green buildings in general and vice versa. Therefore, it is evident that the GPRS is an isolated document which doesn't fit into the current legislation. Although the building codes in Egypt don't promote green concept they also don't obstruct the application of either rating system in Egypt.

\section{Recommendations}

This study has several recommendations for the Unified Building Law and its Executive Appendix, GPRS 2016, and stakeholders. Several articles in both the Unified Building Law and its Executive Appendix need to be modified to promote and ease the application of GBRSs in Egyptian projects. For example, articles 94 and 96 must be adjusted to be inclusive of the minimum area requirements for administrative spaces while also ensuring that they are naturally lit and ventilated to promote a healthier work environment. GPRS 2016 also 
requires a few adjustments in terms of certification level score ranges to reflect the levels of sustainability accurately. Categories should also have minimum requirements which are mandatory in order to ensure that all the aspects are addressed fairly. Architects and contractors must educate themselves on the concepts of sustainability, methods of achieving it, and become well-versed in the techniques which help achieve sustainability.

\section{Limitations of The Study}

This study has limitations as the research was carried out exclusively on office buildings. However, the selection of office buildings was due to the importance of providing sustainable workspaces. The impact of office buildings can have a toll on the surrounding environment. Therefore, considerations must be taken into account during construction in addition to after occupation. Due to the long working hours, a healthy and comfortable work environment helps increase the productivity of the employees. Workspaces require specialized equipment which consume a lot of energy, therefore, energy efficiency is required to reduce costs.

\section{Implementation for Future Studies}

Future studies can evaluate rating systems to identify the most suitable GBRS for different project types in order to have the most efficient rating system for each project type.

\section{REFERENCES}

[1] S.H. Alyami and Y. Rezgui, "Sustainable Building Assessment Tool Development Approach", Sustainable Cities and Society, 2012, pp.5262. https://doi.org/10.1016/j.scs.2012.05.004_(Accessed 7 August 2019).

[2] S.H.E. Abdel Aleem, A.F. Zobaa, and H.M. Abdel Mageed, "Assessment of energy credits for the enhancement of the Egyptian Green Pyramid Rating System", Energy Policy, 2015, pp.407-416. https://doi.org/10.1016/j.enpol.2015.09.033 (Accessed 7 August 2019).

[3] M.G. Ammar, "Evaluation of the Green Egyptian Pyramid", Alexandria Engineering Journal, 2012, pp.293-304. https://doi.org/10.1016/j.aej.2012.09.002 (Accessed 7 August 2019).

[4] S. El Yamany, M. Afifi, and A. Hassan, "Applicability and Implementation of U.S. Green Building Council Rating System (LEED) in Egypt", Procedia Environmental Sciences, 2016, pp.594-604. https://doi.org/10.1016/j.proenv.2016.04.052__ (Accessed 7 August 2019).

[5] Y. He, T. Kvan, M. Liu, and B. Li, "How Green Building Rating Systems Affect Designing Green", Building and Environment, 2018, pp.19-31. http://doi.org/10.1016/j.buildenv.2018.02.007 (Accessed 7 August 2019).

[6] A.K.M. Shamseldin, "Compatibility of Global Environmental Assessment Methods of Buildings with an Egyptian Energy Code", HBRC Journal, 2017, pp.72-82. http://doi.org/10.1016/j.hbrcj.2015.04.002 (Accessed 7 August 2019).

[7] A.K.M. Shamseldin, "Proposal of Adapting the Assessment Weights of GPRS for Different Gated Communities' Positions", HBRC Journal, 2018, pp.224-234. http://doi.org/10.1016/j.hbrcj.2016.02.001 (Accessed 7 August 2019).

[8] H.H. Ali and S.F. Al Nsairat, "Developing a Green Building Assessment Tool for Developing Countries - Case of Jordan", Building and Environment, 2009, pp.1053-1064. http://doi.org/10.1016/j.buildenv.2008.07.015 (Accessed 7 August 2019).
[9] I.M. Illankoon, V.W.Y. Tam, K.N. Le, and L. Shen, "Key Credit Criteria Among International Green Building Rating Tools", Journal of Cleaner Production, 2017, pp.209-220. http://doi.org/10.1016/j.jclepro.2017.06.206 (Accessed 7 August 2019).

[10] S.R. Khese, M.N. Hedaoo, and B.A. Konnur, "A Comparative Study of Rating Systems in Green Building", International Journal of Engineering Research, 2016, pp.134-136.

[11] B.K. Nguyen and H. Altan, "Comparative Review of Five Sustainable Rating Systems", 2011 International Conference on Green Buildings and Sustainable Cities, 2011, pp. 376-386. http://doi.org/10.1016/j.proeng.2011.11.2029 (Accessed 7 August 2019).

[12] D.T. Doan et al., "A Critical Comparison of Green Building Rating Systems", Building and Environment, 2017, pp. 243-260. http://doi.org/10.1016/j.buildenv.2017.07.007 (Accessed 7 August 2019).

[13] O. Awadh, "Sustainability and green building rating systems: LEED, BREEAM, GSAS and Estidama critical analysis", Journal of Building Engineering, 2017, pp.25-29. https://doi.org/10.1016/j.jobe.2017.03.010 (Accessed 17 September 2019)

[14] USGBC, LEED, 2019. https://new.usgbc.org/leed (Accessed 17 September 2019)

[15] USGBC, "LEED 2009 for New Construction and Major Renovations", July 2016.

[16] USGBC, LEED v4 for Building Design and Construction, 25 July 2019 https://new.usgbc.org/ (Accessed 6 August 2019).

[17] USGBC, "LEED v4.1 Building Design and Construction Guide", January 2020.

[18] HBRC, and The Egyptian Green Building Council (EgGBC), The Green Pyramid Rating System (GPRS), First Edition, April 2011. http://egyptgbc.org/ (Accessed 7 August 2019).

[19] HBRC, "Green Pyramids Rating System for New Buildings", Version 2.0, 2016.

[20] USGBC, "LEED Certification Fees", 2019. https://new.usgbc.org/certguide/fees (Accessed 17 September 2019).

[21] People's Assembly, "Unified Building Law no.119 for the year 2008", 2015, Al-Arabi Publishing \& Distribution.

[22] Ministry of Housing, "Executive Appendix of the Unified Building Law, Ministerial decree no.144 - 2009", 2015, Al-Arabi Publishing \& Distribution.

[23] USGBC, Dar Al-Handasah New Premises in Cairo, 2015 https://www.usgbc.org/projects/dar-al-handasah-new-premisescairo?view=scorecard (Accessed 7 December 2019)

[24] GBIG, Dar Al-Handasah New Premises in Cairo, 2015 http://www.gbig.org/activities/leed-1000006741 (Accessed 7 December 2019)

[25] USGBC, Crédit Agricole, 2016. https://www.usgbc.org/projects/creditagricole-egypt-headquarters?view=scorecard (Accessed 7 December 2019)

[26] GBIG, Crédit Agricole Egypt Headquarters, 2016. http://www.gbig.org/activities/leed-1000005034 (Accessed 7 December 2019)

[27] USGBC, Outsourcing Service Building - MB4, 2016. https://www.usgbc.org/projects/outsourcing-service-buildingmb4?view=scorecard (Accessed 7 December 2019)

[28] GBIG, Outsourcing Service Building - MB4, 2016 http://www.gbig.org/activities/leed-1000012410 (Accessed 7 December 2019)

[29] USGBC, EMEC Headquarters, 2018 https://www.usgbc.org/projects/emec-headquarters?view=scorecard (Accessed 7 December 2019)

[30] GBIG, EMEC Headquarters, 2018. http://www.gbig.org/activities/leed1000009192 (Accessed 7 December 2019). 